\title{
Noninvasive estimation of raised intracranial pressure using ocular ultrasonography in liver transplant recipients with acute liver failure -A report of two cases-
}

\author{
Young-Kug Kim, Hyungseok Seo, Jihion Yu, and Gyu-Sam Hwang \\ Department of Anesthesiology and Pain Medicine, Asan Medical Center, University of Ulsan College of Medicine, Seoul, Korea
}

Intracranial pressure (ICP) monitoring is an important issue for liver transplant recipients, since increased ICP is associated with advanced hepatic encephalopathy or graft reperfusion during liver transplantation. Invasive monitoring of ICP is known as a gold standard method, but it can provoke bleeding and infection; thus, its use is a controversial issue. Studies have shown that optic nerve sheath diameter $>5 \mathrm{~mm}$ by ocular ultrasonography is useful for evaluating ICP $>20 \mathrm{mmHg}$ noninvasively in many clinical settings. In this case report, we present experiences of using ocular ultrasound as a diagnostic tool that could detect changes in ICP noninvasively during liver transplantation. (Korean J Anesthesiol 2013; 64: 451-455)

Key Words: Intracranial pressure, Liver transplantation, Ocular ultrasonography.

Hepatic encephalopathy is associated with cerebral edema, increased intracranial pressure (ICP), and subsequent neurologic complications [1]. In addition, graft reperfusion during liver transplantation can increase ICP [2,3]. Thus, ICP monitoring has been proposed for the diagnosis and management of the high ICP during preoperative and intraoperative periods in criticallyill liver transplant recipients [4]. Although direct measurement of ICP using an intraventricular catheter has been known to be a gold standard method for evaluating ICP, it is a highly invasive technique that may not be feasible in many clinical settings due to the severe complications associated with its use, such as hemorrhage and infection [5]. For this reason, noninvasive techniques such as the transcranial Doppler (TCD) have been recommended for evaluating ICP [6]. Recently, ultrasonographic measurement of optic nerve sheath diameter (ONSD) has been increasingly used for the assessment of the risk of high ICP $[7,8]$.

Herein, we report two interesting cases, in which simple and rapid assessment of ONSD by ocular ultrasonography was performed immediately before anesthesia induction or during graft reperfusion in liver transplant recipients recipients with acute liver failure.

Received: June 29, 2012. Revised: August 9, 2012. Accepted: August 10, 2012.

Corresponding author: Gyu-Sam Hwang, M.D., Ph.D., Department of Anesthesiology and Pain Medicine, Asan Medical Center, University of Ulsan College of Medicine, 388-1, Pungnap-2 dong, Songpa-gu, Seoul 138-736, Korea. Tel: 82-2-3010-3989, Fax: 82-2-470-1363, E-mail: kshwang@amc.seoul.kr

(c) This is an open-access article distributed under the terms of the Creative Commons Attribution Non-Commercial License (http:// creativecommons.org/licenses/by-nc/3.0/), which permits unrestricted non-commercial use, distribution, and reproduction in any medium, provided the original work is properly cited. 


\section{Case Reports}

\section{Case 1}

A 53-yr old woman (body weight: $63 \mathrm{~kg}$, height: $162 \mathrm{~cm}$ ) was scheduled for living donor liver transplantation due to acuteon-chronic liver failure. Thirteen years ago, she was diagnosed with hepatitis B related liver cirrhosis. Two days ago, she was intubated due to rapidly developing grade $3-4$ hepatic encephalopathy. In the preoperative evaluation, the chest X-ray, electrocardiography, and echocardiography were within normal range. Her laboratory examination showed $\mathrm{Hb} 7.9 \mathrm{~g} / \mathrm{dl}$, platelet count $27 \times 10^{9} / \mathrm{L}$, prothrombin time 3.5 international normalized ratio, fibrinogen $52 \mathrm{mg} / \mathrm{dl}$, antithrombin III 6\%, sodium $136 \mathrm{mmol} / \mathrm{L}$, potassium $3.9 \mathrm{mmol} / \mathrm{L}$, creatinine $3.8 \mathrm{mg} /$ $\mathrm{dl}$, glucose $163 \mathrm{mg} / \mathrm{dl}$, albumin $3.1 \mathrm{~g} / \mathrm{dl}$, total bilirubin $52.8 \mathrm{mg} /$ dl, and ammonia $205 \mu \mathrm{mol} / \mathrm{L}$. Her Child-Pugh and Model for End-Stage Liver Disease scores were 12 and 49, respectively. However, brain computerized tomography and invasive ICP monitoring could not be performed because the acute exacerbation of her clinical condition requires urgent liver transplantation.

Upon arrival at the operating room, she was still intubated and was in a comatose state. Dopamine of $10 \mu \mathrm{g} / \mathrm{kg} / \mathrm{min}$, dobutamine of $15 \mu \mathrm{g} / \mathrm{kg} / \mathrm{min}$, and norepinephrine of $0.1 \mu \mathrm{g} /$ $\mathrm{kg} / \mathrm{min}$ had been administered continuously. Her systolic/ diastolic/mean arterial blood pressure and heart rate were 100/50/67 mmHg and 80 beats/min, respectively. After establishing the standard monitoring used in our institute, ultrasound ONSD measurements were done by a physician well-trained in ocular ultrasonography before anesthetic induction. Based on the method described in a previous report [8], both eyes were scanned using a 7.5-MHz probe (ProSound SSD-4000, ALOKA, Tokyo, Japan) through closed eyelids with the patient in the supine position. Right and left eyes were scanned in both sagittal and transverse planes, and the ONSD value was calculated by estimating the average results of these measurements. The ONSD was measured $3 \mathrm{~mm}$ posterior to the globe in each eye. Her ONSD just before anesthesia induction was $6.4 \mathrm{~mm}$ (Fig. 1A). Simultaneously, TCD was performed to assess cerebral blood flow velocity and ICP noninvasively. Transtemporal insonation of the left middle cerebral artery was done using a 2-MHz probe (Companion III, Viasys Healthcare, Warwick, UK). TCD measurements showed her systolic/ diastolic/mean cerebral flow velocities were 100/7/37 cm/s (normal reference values of systolic/diastolic/mean velocities [mean \pm SD]: $77.1 \pm 12.23 / 37.4 \pm 7.13 / 50.6 \pm 8.42 \mathrm{~cm} / \mathrm{s})$. The resistance index was 0.93 (normal reference value: $0.52 \pm 0.05$ ) and the pulsatility index was 2.5 (normal reference value: $0.80 \pm$ 0.13), and the second systolic peak (Windkessel effect) was lost, suggesting elevated ICP (Fig. 1B) [6,9]. The bispectral index and suppression ratio were 30 and 20 , respectively, and right and left regional cerebral oxygen saturations were $15 / 15 \%$.

Anesthesia was induced with thiopental and vecuronium, and was maintained using $0.5-1 \%$ isoflurane, a $50 \% \mathrm{O}_{2} /$ air mixture, and continuous infusion with fentanyl and vecuronium. The patient's lungs were ventilated with a tidal volume of $10-12 \mathrm{ml} / \mathrm{kg}$ at a respiratory rate of $10-12$ breaths/ min to maintain hypocarbia $\left(\mathrm{P}_{\mathrm{a}} \mathrm{CO}_{2}: 28-32 \mathrm{mmHg}\right)$ throughout the procedure. Also, mild hypothermia $\left(34-35^{\circ} \mathrm{C}\right)$ was induced, and mannitol of $40 \mathrm{~g}$ was administered every six hours for the management of ICP. After anesthesia induction, her arterial blood gas analysis showed a pH of 7.33, a $\mathrm{P}_{\mathrm{a}} \mathrm{CO}_{2}$ of $28 \mathrm{mmHg}$, a $\mathrm{PaO}_{2}$ of $209 \mathrm{mmHg}$, bicarbonate of $14.8 \mathrm{mEq} / \mathrm{L}$, and base excess of $-10.0 \mathrm{mmEq} / \mathrm{L}$. Intraoperative hemodynamics and laboratory data were shown Table 1.

After finishing surgery, she was transferred to the surgical intensive care unit. On the second postoperative day, right

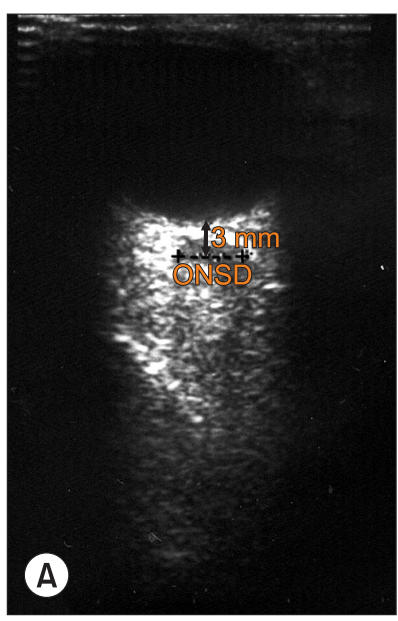

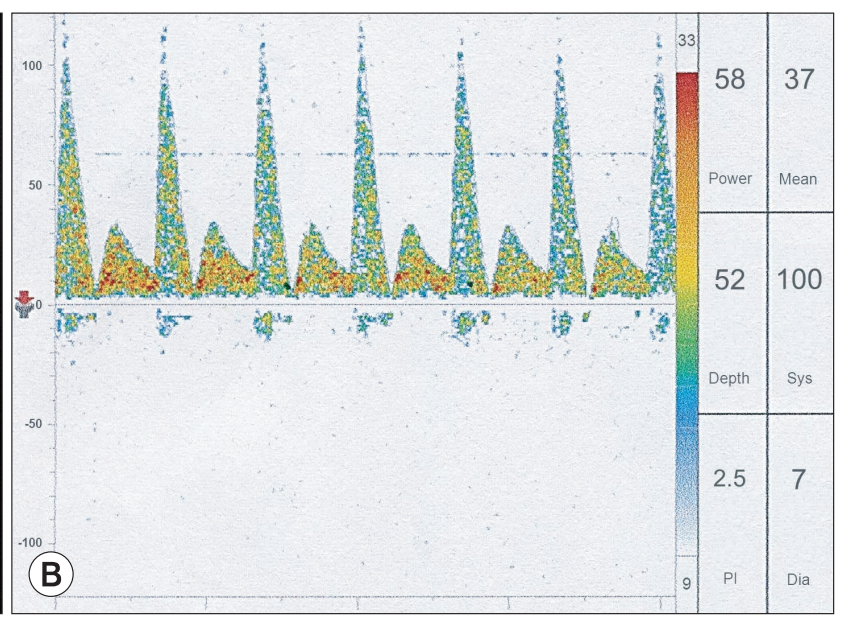

Fig. 1. Optic nerve sheath diameter (ONSD, dash line) measured at $3 \mathrm{~mm}$ behind the optic globe using ocular ultrasonography (A) and cerebral blood flow velocity measured at the left middle cerebral artery using transcranial Doppler (B) in a liver transplant patient with acute-on-chronic liver failure (case 1). Note that the ONSD $(6.4 \mathrm{~mm})$ is dilated, suggesting increased intracranial pressure (ICP). Also, note that the second systolic peak (Windkessel effect) is lost, the systolic peak is sharp and narrow, and the diastolic cerebral blood flow velocity is low, suggesting a high ICP. 
Table 1. Intraoperative Data in Two Recipients

\begin{tabular}{|c|c|c|}
\hline & Case 1 & Case 2 \\
\hline \multicolumn{3}{|l|}{$1 \mathrm{hr}$ after induction of general anesthesia } \\
\hline Arterial blood pressure (systolic/diastolic, mmHg) & $112 / 48$ & $128 / 70$ \\
\hline Heart rate (beats/min) & 82 & 93 \\
\hline Central venous pressure (mmHg) & 8 & 6 \\
\hline Body temperature $\left({ }^{\circ} \mathrm{C}\right)$ & 34.7 & 36.0 \\
\hline Arterial carbon dioxide concentration (mmHg) & 28 & 35 \\
\hline Arterial pH & 7.33 & 7.50 \\
\hline $\mathrm{K}^{+}(\mathrm{mmol} / \mathrm{L})$ & 3.8 & 3.2 \\
\hline \multicolumn{3}{|l|}{ Inotropic use } \\
\hline Dopamine ( $\mu \mathrm{g} / \mathrm{kg} / \mathrm{min})$ & 10 & 0 \\
\hline Dobutamine $(\mu \mathrm{g} / \mathrm{kg} / \mathrm{min})$ & 15 & 0 \\
\hline Norepinephrine $(\mu \mathrm{g} / \mathrm{kg} / \mathrm{min})$ & 0.1 & 0 \\
\hline \multicolumn{3}{|l|}{ Anhepatic phase } \\
\hline Arterial blood pressure (systolic/diastolic, mmHg) & $108 / 47$ & $120 / 74$ \\
\hline Heart rate (beats/min) & 84 & 89 \\
\hline Central venous pressure (mmHg) & 6 & 3 \\
\hline Body temperature $\left({ }^{\circ} \mathrm{C}\right)$ & 34.1 & 34.6 \\
\hline Arterial carbon dioxide concentration $(\mathrm{mmHg})$ & 29 & 35 \\
\hline Arterial $\mathrm{pH}$ & 7.22 & 7.46 \\
\hline $\mathrm{K}^{+}(\mathrm{mmol} / \mathrm{L})$ & 4.3 & 3.2 \\
\hline \multicolumn{3}{|l|}{ Inotropic use } \\
\hline Dopamine ( $\mu \mathrm{g} / \mathrm{kg} / \mathrm{min})$ & 10 & 0 \\
\hline Dobutamine $(\mu \mathrm{g} / \mathrm{kg} / \mathrm{min})$ & 10 & 0 \\
\hline Norepinephrine $(\mu \mathrm{g} / \mathrm{kg} / \mathrm{min})$ & 0.15 & 0 \\
\hline \multicolumn{3}{|c|}{5 min after graft reperfusion } \\
\hline Arterial blood pressure (systolic/diastolic, mmHg) & $102 / 41$ & $124 / 71$ \\
\hline Heart rate (beats/min) & 80 & 91 \\
\hline Central venous pressure (mmHg) & 8 & 5 \\
\hline Body temperature $\left({ }^{\circ} \mathrm{C}\right)$ & 34.0 & 34.0 \\
\hline Arterial carbon dioxide concentration (mmHg) & 30 & 36 \\
\hline Arterial $\mathrm{pH}$ & 7.23 & 7.42 \\
\hline $\mathrm{K}^{+}(\mathrm{mmol} / \mathrm{L})$ & 4.2 & 3.2 \\
\hline \multicolumn{3}{|l|}{ Inotropic use } \\
\hline Dopamine ( $\mu \mathrm{g} / \mathrm{kg} / \mathrm{min})$ & 10 & 0 \\
\hline Dobutamine $(\mu \mathrm{g} / \mathrm{kg} / \mathrm{min})$ & 10 & 0 \\
\hline Norepinephrine ( $\mu \mathrm{g} / \mathrm{kg} / \mathrm{min})$ & 0.15 & 0 \\
\hline Anesthesia duration (hr) & 23 & 14.5 \\
\hline Packed red blood cell amount (unit) & 19 & 13 \\
\hline Crystalloid amount (ml) & 10,900 & 7,200 \\
\hline
\end{tabular}

and left pupil size were $3 / 3 \mathrm{~mm}$. According to Glasgow coma scale evaluation, eye opening score was 4 , best motor response score was 4 , best verbal response score was not evaluated due to endotracheal intubation. Bispectral index score ranged from 70 to 90 . However, on the third postoperative day, she was developed septic shock, and the patient died by septic shock on the fourth postoperative day.

\section{Case 2}

A 40-yr old man (body weight: $73 \mathrm{~kg}$, height: $172 \mathrm{~cm}$ ) was scheduled for living donor liver transplantation surgery due to acute liver failure. One week ago, he developed grade 1 hepatic encephalopathy. In the preoperative evaluation, electrocardiography and echocardiography were within normal range.
Chest X-ray showed mild pleural effusion on both lungs. His laboratory examination showed $\mathrm{Hb} 9.9 \mathrm{~g} / \mathrm{dl}$, platelet count 107 $\times 10^{9} / \mathrm{L}$, prothrombin time 2.2 international normalized ratio, fibrinogen $82 \mathrm{mg} / \mathrm{dl}$, antithrombin III 12\%, sodium $135 \mathrm{mmol} / \mathrm{L}$, potassium $3.0 \mathrm{mmol} / \mathrm{L}$, creatinine $1.1 \mathrm{mg} / \mathrm{dl}$, glucose $144 \mathrm{mg} /$ $\mathrm{dl}$, albumin $3.0 \mathrm{~g} / \mathrm{dl}$, total bilirubin $23.1 \mathrm{mg} / \mathrm{dl}$, and ammonia 82 $\mu \mathrm{mol} / \mathrm{L}$. Her Child-Pugh and Model for End-Stage Liver Disease scores were 12 and 28 , respectively.

Upon arrival at the operating room, his mental state was alert. His systolic/diastolic arterial blood pressure and heart rate were 132/68 mmHg and 98 beats/min, respectively. After establishing institutional standard monitoring, an ultrasound ONSD measurement was done by a physician well-trained in ocular ultrasonography. His ONSD just before anesthesia induction was $4.8 \mathrm{~mm}$ (Fig. 2A). The bispectral index and suppression ratio were 98 and 0, respectively, and right and left regional cerebral oxygen saturations were 43 and $44 \%$, respectively.

General anesthesia was induced and maintained by the standard protocol at our institute. His lungs were ventilated with a tidal volume of $8-10 \mathrm{ml} / \mathrm{kg}$ at a respiratory rate of 10 breaths/ $\min \left(\mathrm{P}_{\mathrm{a}} \mathrm{CO}_{2}, 35-40 \mathrm{mmHg}\right)$. Intraoperative hemodynamics and laboratory data were shown Table 1 . He experienced severe hypotension (systolic/diastolic arterial blood pressure: 62/48 $\mathrm{mmHg}$ ) and bradycardia (56 beats/min) after graft reperfusion, and was treated with epinephrine $(20 \mu \mathrm{g})$, after which systolic/ diastolic arterial blood pressure $(122 / 72 \mathrm{mmHg})$ and heart rate (92 beats/min) rapidly recovered to within the normal limit. His ONSD was dilated at $5.7 \mathrm{~mm}$ to $5 \mathrm{~min}$ after reperfusion (Fig. 2B), and hyperventilation was performed with a tidal volume of 12 $\mathrm{ml} / \mathrm{kg}$ at a respiratory rate of 13 breaths $/ \mathrm{min}\left(\mathrm{P}_{\mathrm{a}} \mathrm{CO}_{2}, 28 \mathrm{mmHg}\right)$. His ONSD decreased to $5.1 \mathrm{~mm}$ at $30 \mathrm{~min}$ after reperfusion (Fig. $2 \mathrm{C}$ ), and ventilation was adjusted to maintain normocarbia until the end of surgery. He was moved to the surgical intensive care unit after surgery, and then transferred to a general ward without any complications on the seventh postoperative day.

\section{Discussion}

Noninvasive estimation of ultrasonographic ONSD has been reported to be a useful method for evaluating elevated ICP (defined as ICP $>20 \mathrm{mmHg}$ ). In case 1 of a liver transplant recipient with grade 4 hepatic encephalopathy, we evaluated elevated ICP using ultrasonographic ONSD and TCD flow velocity before anesthesia induction. In case 2 , we evaluated ONSD during the graft reperfusion period. This patient had grade 1 hepatic encephalopathy and showed a normal ONSD before anesthesia induction and had a dilated ONSD immediately after reperfusion. We also found that the dilated ONSD decreased after hyperventilation. 

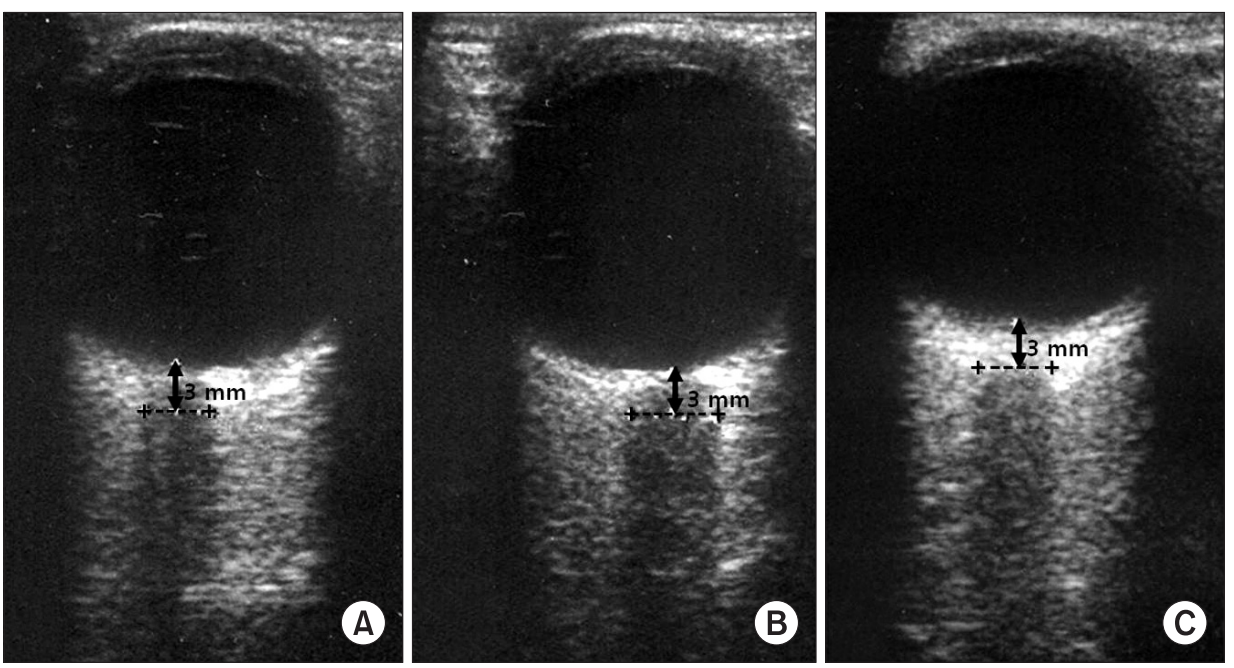

Fig. 2. Changes in optic nerve sheath diameters (ONSD, dash line) (A) before induction of general anesthesia, (B) $5 \mathrm{~min}$, and (C) $30 \mathrm{~min}$ after graft reperfusion in a liver transplant recipient with acute liver failure (A: $4.8 \mathrm{~mm}, \mathrm{~B}: 5.7$ $\mathrm{mm}, \mathrm{C}: 5.1 \mathrm{~mm}$ ) (case 2). Note that the dilated ONSD $>5 \mathrm{~mm}$ after reperfusion decreases $30 \mathrm{~min}$ after reperfusion.

Advanced hepatic encephalopathy (grade 3 and 4) is associated with the development of cerebral edema, which is usually diagnosed by detecting an increased ICP [1]. Indeed, cerebral edema and a high ICP can decrease cerebral perfusion pressure, resulting in brain damage and mortality. During liver transplantation, the graft reperfusion period is critical due to the high risk of acute hemodynamic changes, which can range from a mild hypotensive episode to profound cardiovascular collapse, known as the postreperfusion syndrome. Furthermore, the reperfusion of a new graft can induce an increase in ICP, which is possibly related to cerebral vessel dilatation and vasoactive substances $[2,10,11]$. Thus, these observations suggest that liver transplant recipients are particularly exposed to high ICP and decreased cerebral perfusion pressure during the perioperative period, and that intraoperative ICP monitoring is important in patients with high ICP-related neurologic abnormalities.

Invasive monitoring of ICP is known to be a gold standard method; however, it may not be feasible in recipients undergoing liver transplantation, since severe coagulopathy can develop as a result of preexisting coagulopathy, dilutional coagulopathy, fibrinolysis, hypocalcemia, hypothermia, intravascular coagulation, or the heparin effect during liver transplantation surgery, which exposes patients to a greater risk of hemorrhage.

The optical nerve sheath is continuous with the dura mater of the brain, and has a subarachnoid space [12]. The subarachnoid space in the optic nerve sheath communicates with the craniospinal subarachnoid space, and thus ONSD can be influenced by changes in cerebrospinal fluid pressure in the cranial cavity [12]. Moreover, it is well known that ONSD measured $3 \mathrm{~mm}$ behind the optic globe is increased by elevated ICP [13]. Based on these considerations, noninvasive measurement of ONSD has been increasingly attempted for monitoring ICP in many clinical settings [8]. Especially, ultrasonographic ONSD assessment has proven to be useful for monitoring high ICP in patients with brain injury, idiopathic intracranial hypertension, and spontaneous intracranial hemorrhage $[7,13,14]$.

Moretti et al. [7] reported that there is a linear correlation between ONSD and an invasive ICP measurement, and that a significant reduction of the ONSD occurs after cerebrospinal fluid drainage for the management of high ICP (ONSD: from 5.89 to $5.0 \mathrm{~mm}$ ). They also suggested that the optimal cut off value of ONSD to predict ICP $>20 \mathrm{mmHg}$ is $5.2 \mathrm{~mm}$ [7]. In another study, the best cut off value of ONSD for predicting elevated ICP was reported to be in the range of 5.0-5.9 $\mathrm{mm}$ in neurocritically ill adults [8]. However, there is limited information available about the usefulness of ultrasonographic ONSD assessment in liver transplant recipients, who may experience severe coagulopathy and high ICP during liver transplantation. We found that ultrasonographic ONSD was 6.4 $\mathrm{mm}$ before induction in one recipient (case 1) with advanced hepatic encephalopathy and $5.7 \mathrm{~mm}$ after graft reperfusion in another recipient (case 2), indicating high ICP. Based on these findings, we believe that noninvasive estimation of ocular ultrasonography can provide important information about ICP during liver transplantation.

Treatment strategies such as hyperventilation, hypothermia, and mannitol administration have been employed for the management of high ICP. Especially, mild hyperventilation prior to graft reperfusion was shown to prevent the increase in ICP above the pre-reperfusion level in TCD flow velocity, suggesting that hyperventilation may be effective in reducing reperfusion-related high ICP during liver transplantation [15]. In case 2, the dilated ONSD observed after graft reperfusion was decreased by hyperventilation. It is not clear whether short- 
term hyperventilation induces directly a reduction in ONSD. However, we consider that it may, at least in part, influence the change in ONSD. This finding suggests that ultrasonographic ONSD measurement provides useful information about the effectiveness of treatments used to lower ICP in liver transplant recipients with high ICP.

TCD can also be used to evaluate high ICP noninvasively by measuring cerebral blood flow velocity. TCD findings in case 1 agree with those of a report by Aggarwal et al. [9], in which high ICP induced a loss of the second systolic peak (Windkessel effect) and a sharpness of the systolic peak in the TCD waveform. Also, TCD-derived indices such as diastolic and mean cerebral blood flow velocities have been used for the calculation of ICP [6]. Based on the previous report, ICP can be assessed noninvasively by TCD using the following formula [6]: estimated ICP = the mean arterial blood pressure $\times(1-$ diastolic flow velocity/mean flow velocity $)-14$. The ICP calculated by the formula was $40 \mathrm{mmHg}$ in our liver transplant recipient (case 1), supporting that the dilated ONSD is associated with ICP $>20 \mathrm{mmHg}$.

In this case report, we can not examine simultaneously ONSD and TCD at several specific time points (such as anhepatic phase, post-reperfusion phase, or neohepatic phase) during liver transplantation. Further studies will be required to evaluate the ICP status by simultaneous examinations of ONSD and TCD at specific time points. In addition, a possible limitation of ocular ONSD measurement is intra-observer or inter-observer variability, which is dependent on clinical experience and skill of observers. However, we consider that ONSD measurements are highly reliable because they were done by a physician welltrained in ocular ultrasonography.

In summary, the cases described in this report suggest that ultrasound measurement of ONSD may have clinical relevance as a feasible diagnostic tool for the noninvasive, rapid, and simple detection of increased ICP in liver transplant recipients.

\section{References}

1. Ede RJ, Williams RW. Hepatic encephalopathy and cerebral edema. Semin Liver Dis 1986; 6: 107-18.
2. Detry O, Arkadopoulos N, Ting P, Kahaku E, Margulies J, Arnaout $\mathrm{W}$, et al. Intracranial pressure during liver transplantation for fulminant hepatic failure. Transplantation 1999; 67: 767-70.

3. Keays R, Potter D, O'Grady J, Peachey T, Alexander G, Williams R. Intracranial and cerebral perfusion pressure changes before, during and immediately after orthotopic liver transplantation for fulminant hepatic failure. Q J Med 1991; 79: 425-33.

4. Steadman RH, Van Rensburg A, Kramer DJ. Transplantation for acute liver failure: perioperative management. Curr Opin Organ Transplant 2010; 15: 368-73.

5. Lang EW, Chesnut RM. Intracranial pressure. Monitoring and management. Neurosurg Clin N Am 1994; 5: 573-605.

6. Czosnyka M, Matta BF, Smielewski P, Kirkpatrick PJ, Pickard JD. Cerebral perfusion pressure in head-injured patients: a noninvasive assessment using transcranial Doppler ultrasonography. J Neurosurg 1998; 88: 802-8.

7. Moretti R, Pizzi B, Cassini F, Vivaldi N. Reliability of optic nerve ultrasound for the evaluation of patients with spontaneous intracranial hemorrhage. Neurocrit Care 2009; 11: 406-10.

8. Moretti R, Pizzi B. Ultrasonography of the optic nerve in neurocritically ill patients. Acta Anaesthesiol Scand 2011; 55: 644-52.

9. Aggarwal S, Brooks DM, Kang Y, Linden PK, Patzer JF 2nd. Noninvasive monitoring of cerebral perfusion pressure in patients with acute liver failure using transcranial doppler ultrasonography. Liver Transpl 2008; 14: 1048-57.

10. Doblar DD, Frenette L, Poplawski S, Gelman S, Boyd G, Ranjan D, et al. Middle cerebral artery transcranial Doppler velocity monitoring during orthotopic liver transplantation: changes at reperfusion--a report of six cases. J Clin Anesth 1993; 5: 479-85.

11. Pott F, Larsen FS, Ejlersen E, Linkis P, Jorgensen LG, Secher NH. Cerebral perfusion during human liver transplantation. Clin Physiol 1995; 15: 119-30.

12. Liu D, Kahn M. Measurement and relationship of subarachnoid pressure of the optic nerve to intracranial pressures in fresh cadavers. Am J Ophthalmol 1993; 116: 548-56.

13. Soldatos T, Chatzimichail K, Papathanasiou M, Gouliamos A. Optic nerve sonography: a new window for the non-invasive evaluation of intracranial pressure in brain injury. Emerg Med J 2009; 26: 630-4.

14. Bauerle J, Nedelmann M. Sonographic assessment of the optic nerve sheath in idiopathic intracranial hypertension. J Neurol 2011; 258: 2014-9.

15. Doblar DD, Lim YC, Frenette L, Poplawski S, Ranjan D, Ronderos J. The effect of acute hypocapnia on middle cerebral artery transcranial Doppler velocity during orthotopic liver transplantation: changes at reperfusion. Anesth Analg 1995; 80: 1194-8. 